\title{
Comparison of Clinical Characteristics and Pregnancy and Neonatal Outcomes Between Turkish Citizens and Syrian Refugees with High-Risk Pregnancies
}

\author{
Ugurcan Sayili ${ }^{1}\left[\right.$ Cigdem Ozgur $^{2}\left([) \cdot\right.$ Oznur Bulut Gazanfer $^{3}\left[\right.$ Abdullah Solmaz $^{3,4}$ (1)
}

Accepted: 28 September 2021 / Published online: 11 October 2021

(c) The Author(s), under exclusive licence to Springer Science+Business Media, LLC, part of Springer Nature 2021

\begin{abstract}
Refugee women experience more negative pregnancy and neonatal outcomes, such as low birth weight and preterm birth. The aim of the present study was to compare the clinical characteristics and pregnancy and neonatal outcomes between Turkish citizens and Syrian refugees with high-risk pregnancies. This prospective cohort study was conducted between March and December 2020 in Sanliurfa, Turkey. The maternal characteristics and pregnancy and neonatal outcomes were compared between the two groups. In this study, a total of 302 high-risk pregnant women (233 Turkish citizens and 69 Syrian refugees) were included. Parity and pregnancy spacing shorter than 2 years were significantly higher in Syrian refugees. Age, previous abortion or miscarriage and rates of cesarean section $(\mathrm{C} / \mathrm{S})$ were significantly higher in Turkish citizens. The live birth (Turkish: $94.8 \%$ vs Syrian: $92.8 \%$ ), preterm birth (Turkish: 10\% vs Syrian: 9.4\%), low birth weight (Turkish: $7.7 \%$ vs Syrian: $3.1 \%$ ) rates and birth weight (g) (Turkish: $3097.5 \pm 501.3 \mathrm{~g}$; Syrian: $2980.2 \pm 395.0 \mathrm{~g}$ ) were not significantly different between Turkish citizens and Syrian refugees with high-risk pregnancy. Similar pregnancy and neonatal outcomes could be attributed to the Syrians receiving adequate and free maternity care, similar to the Turkish citizens.
\end{abstract}

Keywords High-risk pregnancy $\cdot$ Neonatal outcomes $\cdot$ Obstetric outcomes $\cdot$ Syrian refugees $\cdot$ Turkey

\section{Introduction}

Ugurcan Sayili

ugurcan.sayili@istanbul.edu.tr

Cigdem Ozgur

cigdem.aslaner@istanbul.edu.tr

Oznur Bulut Gazanfer

oznurbulut@yahoo.com

Abdullah Solmaz

dr.solmaz@hotmail.com

1 Karakopru District Health Directorate, Republic of Turkey Ministry of Health, Sanliurfa, Turkey

2 Haliliye District Health Directorate, Republic of Turkey Ministry of Health, Sanliurfa, Turkey

3 Public Health Services Presidency, Sanliurfa Provincial Health Directorate, Republic of Turkey Ministry of Health, Sanliurfa, Turkey

4 Department of Pediatrics, School of Medicine, Harran University, Sanliurfa, Turkey
According to United Nations (UN) data, due to decreased security since 2011, more than 5.6 million people have had to immigrate from Syria to Lebanon, Turkey, Jordan and other countries, and millions more were displaced inside Syria [1]. Turkey hosts the largest number $(3,632,363)$ of registered Syrian refugees because of the ease of transportation to Turkey [2].

In 2002, the World Health Organization (WHO) recommended at least four follow-ups, the first one between 8 and 12 weeks and no later than 16 weeks and an additional 3 follow-ups between 24 and 38 weeks [3]. Currently, the WHO recommends eight antenatal care sessions for pregnant women, first during the first 12 weeks of pregnancy and then at 20, 26, 30, 34, 36, 38 and 40 weeks [4]. According to the "Prenatal Care Management Guideline" published by the Turkish Ministry of Health, a minimum of four followups (first during the first 12 weeks of pregnancy and then at 18-24, 28-32, 36-38 weeks) should be performed during pregnancies without any problems, and this number should be increased and a referral to the relevant specialist 
should be provided when necessary in pregnancies with certain risk factors. According to the "Prenatal Care Management Guideline", detailed follow-ups, including anamnesis, physical examination, laboratory tests, fetal screening tests, iron and vitamin D supplementation, hepatitis B and tetanus prophylaxis, information and health education are performed. Follow-ups are performed free of charge in gynecology clinics of public hospitals and family health centers or immigrant health centers during appropriate pregnancy week interval [5].

Syrian refugees experience psychological or physical traumas and are in a disadvantaged and vulnerable group in sociocultural terms due to low incomes and poor living conditions [6-8]. Their access to reproductive healthcare services may also be limited by adaptation, antenatal care awareness, legal status and sociocultural factors such as language barriers and traditional beliefs [9]. Therefore, most pregnant Syrian refugees are unable to conform to the suggested WHO and Turkish prenatal care guidelines, which is reflected by negative pregnancy outcomes [10-13]. Previous studies reported increased negative maternal and neonatal outcomes, such as low birth weight, preterm birth, and postpartum bleeding, in the pregnancies of Syrian refugees [9, 14].

Syrian refugees have free access to immigrant health centers and all hospitals, and these women can receive all pregnancy healthcare services free of charge in Turkey. They can also receive direct health services in their own languages at immigrant healthcare centers and with translation services at hospitals [15].

According to Turkish Statistical Institute data, although the province of Sanliurfa has a population of 2,115,256, constituting $2.5 \%$ of Turkey's population, the number of deliveries was 5.3\% of all deliveries in Turkey [16]. Located on the Turkish-Syrian border, Sanliurfa is one of the first entrance points for refugees. Sanliurfa hosts $11.5 \%(423,625)$ of $3,671,277$ registered refugees in Turkey. The ratio of Syrian immigrants $(423,625)$ to Turkish citizens $(2,108,013)$ in Sanliurfa is $20.1 \%$ [2].

Given the literature on refugee outcomes, our hypothesis is as follows: (1) there is a significant difference in birth weight, rate of preterm birth and clinical characteristics between Turkish citizens and Syrian refugees. To our knowledge, this study is the first cohort study to evaluate pregnancy and neonatal outcomes between Turkish citizens and Syrian refugees with high-risk pregnancies. The aim of the present study was to compare the clinical characteristics and pregnancy and neonatal outcomes between Turkish citizens and Syrian refugees with high-risk pregnancies.

\section{Method}

\section{Study Design and Population}

This prospective cohort study was conducted between March and December 2020 in Sanliurfa province, Turkey. The study data were obtained from the project "Diagnosis and Follow-up of at Risk/High-risk Pregnancies among Women in Syrian and Host Communities", which was conducted in cooperation with the Sanliurfa Provincial Health Directorate and the WHO County Office (Turkey) in Sanliurfa in 2020. The project aim was to provide training, observations and follow-ups through pregnancy information classes for high-risk pregnancies. Followups and training were provided on the phone due to both COVID-19 pandemic isolation precautions and pregnant women avoiding health centers. In cases of emergencies or problems among pregnant women, suitable transfers of the pregnant women were provided by contacting a gynecologist and perinatologist through the project coordination office. During the project, women's antenatal visits to gynecologists and family physicians and their pregnancy-related problems (not being able to find a medical examination or go to the hospital, pregnancy-related health problems, etc.) were followed up, and pregnancyrelated training was provided on the phone. To encourage participation by the pregnant women, maternity bags and labor sets (diapers, cleaning towels, baby shampoo, antirash cream, blankets, bath towels, mouth wipes, baby suits, baby pants with booties, aprons, hats and gloves) were given to these women after delivery.

The sample size was determined for key study objectives based on birth weight using OpenEpi with the following parameters: confidence interval (95\% CI) 95\%, power: $80 \%$, ratio of Syrian/Turkish women: $1 / 3$, mean birthweight $_{\mathrm{TR}}: 3100 \mathrm{~g}$, mean birthweight ${ }_{\mathrm{SY}}: 2900 \mathrm{~g}$, and standard deviation: 500 based on research in the literature $[9,14,15]$. The sample size was a total of 277 high-risk pregnant women, with 213 Turkish citizens and 64 Syrian refugees.

The study population included a total of 300 high-risk pregnant women, with 230 Turkish and 70 Syrian refugees. Participants who had any of the risk factors and a pregnancy at weeks $<24$ were included in the study; the risk factors were age $<18$ or $>35$, first pregnancy, negative obstetric history (preterm birth, infant death, stillbirth, or recurrent miscarriage), pregnancy complications, chronic disease, pregnancy spacing shorter than 2 years, and greater than five pregnancies. The exclusion criteria in the study were moving outside Sanliurfa or not answering project phone calls.

Among the individuals reported to have high-risk pregnancies by family health centers, immigrant health centers 
and hospitals, women with a pregnancy at $<24$ weeks were invited to participate in the project. Participant recruitment started in March 2020 and ended when the targeted number of participants was reached in April 2020. Seven extra participants were included because of seven women who had stillbirths or miscarriages within the first month of the project. Five participants moved outside Sanliurfa or did not answer the project phone calls. Thus, the project included 302 participants. All the project participants were included in the study (Fig. 1).

At the beginning of the project, face-to-face interviews were conducted with informed consent forms and data collection forms at the district health directorates. At the end of the project, a face-to-face meeting was held to obtain pregnancy and neonatal outcomes and to give gifts to the participants. There were periods when full closures due to the COVID-19 pandemic were implemented during the project's timeframe. Trainings and follow-ups were made on the phone; however, those who agreed to apply to the district health directorates were followed up face to face at appropriate times.

\section{Variables}

The baseline characteristics, recent pregnancy information, obstetric history, pregnancy and neonatal outcomes were compared between groups. The baseline characteristics and recent pregnancy information included the participant age,

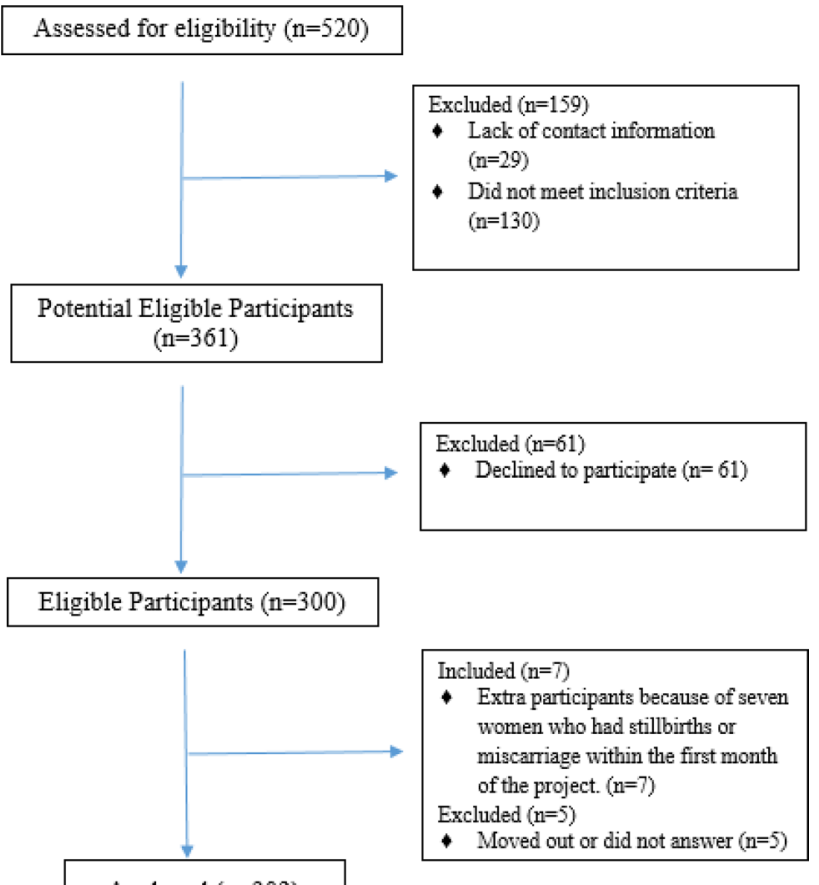

Analyzed ( $\mathrm{n}=302$ )

Fig. 1 Flowchart of study participants antenatal visit with gynecologist, gestational week at first antenatal visit with gynecologist, and gestational week at first follow-up in this study. The obstetric history included gravidity, parity, abortion or miscarriage, age at first pregnancy, pregnancy spacing shorter than 2 years, history of stillbirth or infant death, history of preterm birth, history of having a baby born with an anomaly, history of hospitalization for hypertension, concurrent chronic disease and previous cesarean section $(\mathrm{C} / \mathrm{S})$. The pregnancy attitude included planned and intended pregnancy, planning to become pregnant again and preferred mode of delivery. The pregnancy and neonatal outcomes included the pregnancy result (live birth, stillbirth, or miscarriage), mode of delivery (vaginal, $\mathrm{C} / \mathrm{S}$ ), gestational week ( $<37$ weeks: preterm birth; $\geq 37$ weeks: term birth), birth weight $(\mathrm{g})$, and low birth weight $(<2500 \mathrm{~g})$.

The baseline characteristics, recent pregnancy information, obstetric history, pregnancy attitude, pregnancy and neonatal outcomes were compared between Turkish citizens and Syrian refugees with high-risk pregnancies.

Low birth weight was defined as a birth weight lower than $2500 \mathrm{~g}$. If the answer to "Would you describe your pregnancy as unplanned or unintended?" is "no", it was categorized as a planned and intended pregnancy. Planning to become pregnant again was determined using the question "Would you plan to become pregnant again?", and the answer option was "yes, no, I am not decided". Mean values were used for twin births. There were no missing data for this information.

\section{Statistical Analysis}

The Statistical Package for the Social Sciences version 21.0 for Windows (IBM Corp., Armonk, NY, USA) software package was used for data evaluation and analysis. Categorical variables are presented as frequencies (n) and percentages (\%), and numeric variables are presented as the mean \pm standard deviation and median (interquartile range (IQR)) values. The Kolmogorov-Smirnov test was used for normality analysis. The chi-square test was used to compare the distribution of categorical variables between groups. Independent samples t tests and Mann-Whitney U tests were used to compare continuous variables between two independent groups. We also conducted logistic and linear regression analyses to evaluate whether the groups were risk factors for pregnancy and neonatal outcomes. A value of $p<0.05$ was accepted to be statistically significant.

\section{Results}

In this study, a total of 302 women with high-risk pregnancies (233 Turkish citizens and 69 Syrian refugees) were included. The gestational week at the first follow-up was not 
significantly different (p: 0.692). The demographic and clinical characteristics of the participants are shown in Table 1.

The mean age of the Turkish citizens was $31.4 \pm 6.9$ years and $28.1 \pm 6.4$ years for the Syrian refugees $(\mathrm{p}<0.001)$.

Ages at first pregnancy were significantly lower in the Syrian refugees (p: 0.034). Gravidas were not significantly different, while $45.5 \%$ of Turkish citizens and $50.7 \%$ of Syrian refugees $\mathrm{had} \geq 5$ gravidas (p: 0.326 ). The parity of Syrian refugees was significantly higher than that of Turkish citizens (p: 0.010). The previous abortion or miscarriage rate was $48.5 \%$ in Turkish citizens and $34.8 \%$ in Syrian refugees (p: 0.044). A total of $69.4 \%$ of Syrian pregnant women had pregnancy spacings shorter than 2 years, which was significantly higher than that of the Turkish citizens (52.7\%; p: 0.020). The history of stillbirth, infant death and preterm birth were not significantly different between Turkish citizens and Syrian refugees with high-risk pregnancies ( $p>0.05)$. The planned and intended pregnancy rate was significantly higher for Syrians, with $85.5 \%$ for Syrian refugees and $66.5 \%$ for Turkish citizens (p: 0.002). The proportion of women planning to become pregnant again was $52.2 \%$ among Syrian refugees and $22.7 \%$ among Turkish citizens $(\mathrm{p}<0.001)$. The rate of previous $\mathrm{C} / \mathrm{S}$ was significantly higher for Turkish citizens (40.1\%) than for Syrian refugees (21.7\%) (p: 0.005 ). While $49.8 \%$ of Turkish citizens preferred normal vaginal delivery and $42.9 \%$ preferred $\mathrm{C} / \mathrm{S}$ delivery, $79.7 \%$ of

Table 1 Characteristics of Syrian and Turkish women with high-risk pregnancies

\begin{tabular}{|c|c|c|c|}
\hline & $\begin{array}{l}\text { Turkish Citizens (n: } \\
\text { 233) }\end{array}$ & $\begin{array}{l}\text { Syrian Refugees (n: } \\
69 \text { ) }\end{array}$ & $\mathrm{p}$ value \\
\hline Age (years) $($ mean \pm std $)$ & $31.4 \pm 6.9$ & $28.1 \pm 6.4$ & $<0.001^{\dagger}$ \\
\hline Age at first pregnancy (years) (mean \pm std) & $21.8 \pm 4.1$ & $20.6 \pm 4.1$ & $0.034^{\dagger}$ \\
\hline Gestational week at first follow-up in this study (mean \pm std) & $17.7 \pm 4.3$ & $18.0 \pm 2.9$ & $0.692^{\dagger}$ \\
\hline \multicolumn{4}{|l|}{ Gravida $(n, \%)$} \\
\hline First pregnancy & $15(6.4 \%)$ & $7(10.1 \%)$ & \\
\hline $1-4$ & $112(48.1 \%)$ & $27(39.1 \%)$ & $0.326^{+}$ \\
\hline$\geq 5$ & $106(45.5 \%)$ & $35(50.7 \%)$ & \\
\hline \multicolumn{4}{|l|}{$\operatorname{Parity}(n, \%)$} \\
\hline Nulliparous & $20(8.6 \%)$ & $8(11.6 \%)$ & \\
\hline $1-2$ & $82(35.2 \%)$ & $11(15.9 \%)$ & $0.010^{\ddagger}$ \\
\hline$\geq 3$ & $131(56.2 \%)$ & $50(72.5 \%)$ & \\
\hline Previous abortion or miscarriage (n, \%) & $113(48.5 \%)$ & $24(34.8 \%)$ & $0.044^{\ddagger}$ \\
\hline Pregnancy spacing shorter than 2 years (n, \%) & $116(52.7 \%)$ & $43(69.4 \%)$ & $0.020^{\ddagger}$ \\
\hline History of stillbirth or infant death (n, \%) & $38(16.3 \%)$ & $10(14.5 \%)$ & $0.717^{+}$ \\
\hline History of preterm birth (22-37 weeks) (n, \%) & $35(15.0 \%)$ & $5(7.3 \%)$ & $0.094^{\ddagger}$ \\
\hline History of baby born with an anomaly (n, \%) & $11(4.7 \%)$ & $6(8.7 \%)$ & $0.208^{\ddagger}$ \\
\hline History of hospitalization for hypertension $(\mathrm{n}, \%)$ & $13(5.6 \%)$ & $2(2.9 \%)$ & $0.368^{\ddagger}$ \\
\hline Antenatal visit with gynecologist (n, \%) & $211(90.6 \%)$ & $64(92.8 \%)$ & $0.574^{\ddagger}$ \\
\hline Gestational week at first antenatal visit with gynecologist median (IQR) & $6(4-8)$ & $8(4-12)$ & $0.002^{\S}$ \\
\hline Concurrent chronic disease (n, \%) & $51(21.9 \%)$ & $1(1.5 \%)$ & $<0.001^{\text {末 }}$ \\
\hline Planned and intended pregnancy (n, \%) & $155(66.5 \%)$ & $59(85.5 \%)$ & $0.002^{*}$ \\
\hline \multicolumn{4}{|l|}{ Planning to become pregnant again $(n, \%)$} \\
\hline Undecided & $61(26.2 \%)$ & $12(17.4 \%)$ & $<0.001^{\text {* }}$ \\
\hline Yes & $53(22.7 \%)$ & $36(52.2 \%)$ & \\
\hline No & $119(51.1 \%)$ & $21(30.4 \%)$ & \\
\hline Previous C/S (n, \%) & $93(40.1 \%)$ & $15(21.7 \%)$ & $0.005^{\ddagger}$ \\
\hline \multicolumn{4}{|l|}{ Preferred mode of delivery } \\
\hline Undecided & $17(7.3 \%)$ & $3(4.4 \%)$ & 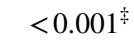 \\
\hline Normal vaginal delivery & $116(49.8 \%)$ & $55(79.7 \%)$ & \\
\hline $\mathrm{C} / \mathrm{S}$ & $100(42.9 \%)$ & $11(15.9 \%)$ & \\
\hline
\end{tabular}

$C / S$ cesarean section, $I Q R$ interquartile range; and mean \pm std: mean \pm standard deviation

${ }^{\dagger}$ Independent Samples $T$ Test

$\ddagger$ Chi-Square Test

${ }^{\S}$ Mann-Whitney U Test were applied 
the Syrian refugees preferred normal vaginal delivery and $15.9 \%$ preferred $\mathrm{C} / \mathrm{S}$ delivery $(\mathrm{p}<0.001)$.

The maternal and neonatal outcomes of the groups are shown in Table 2 and Fig. 2. In follow-ups, 94.8\% of Turkish citizens and $92.8 \%$ of Syrian refugees experienced live births (p: 0.616). The rate of $\mathrm{C} / \mathrm{S}$ was significantly higher for Turkish citizens (58.9\%) than for Syrian refugee women $(23.1 \%)$ (p: 0.001). The mean gestational week of the Turkish citizens was $37.94 \pm 1.51$ weeks and $37.50 \pm 1.23$ years in the Syrian refugees. The rate of preterm birth ( $<37$ weeks) was $10.0 \%$ in Turkish citizens and $9.4 \%$ in Syrian refugees. The rate of preterm birth was not significantly different according to nationality ( $\mathrm{p}: 0.891$ ). The mean birth weight was $3097.5 \pm 501.3 \mathrm{~g}$ for Turkish citizens and $2980.2 \pm 395.0 \mathrm{~g}$ for Syrian refugees, which was a nonsignificant difference (p: 0.086). Similarly, the rate of low birth weight was $7.7 \%$ in Turkish citizens and 3.1\% in Syrian refugees, but the difference was not significant (p: 0.197).

The pregnancy results for Turkish citizens and Syrian refugees were evaluated as independent risk factors with propensity score adjustment. The propensity score between Turkish citizens and Syrian refugees was calculated using the following parameters that may affect pregnancy and neonatal outcomes, with significant differences between Turkish citizens and Syrian refugees: age, parity, abortion or miscarriage, pregnancy spacing shorter than 2 years, previous $\mathrm{C} / \mathrm{S}$, chronic disease, and gestational week at first antenatal visit with gynecologist. There were no significant differences in pregnancy and neonatal outcomes between Turkish and
Syrian refugees with propensity score adjustment, similar to the univariate analysis (Table 3).

\section{Discussion}

In the present study, we aimed to compare the clinical characteristics and pregnancy and neonatal outcomes between Turkish citizens and Syrian refugees with high-risk pregnancies. The rates of pregnancy and neonatal outcomes (live birth, preterm birth, and birth weight) were not significantly different between Turkish citizens and Syrian refugees.

The rate of live births among these high-risk pregnancies was not significantly different in this study $(94.8 \%$ of Turkish citizens and $92.8 \%$ of Syrian refugees). In a study conducted in Turkey, Kiyak et al. reported similar stillbirth rates between Turkish and Syrian pregnant women [6]; however, some European studies reported increased stillbirth prevalence among refugees [7]. The mean birth weight was $2980.2 \pm 395.0$ among Syrian refugees and 3097.5 \pm 501.3 among Turkish citizens in this study. Additionally, while $3.1 \%$ of the babies of Syrian refugees had low birth weights, this rate was $7.7 \%$ among Turkish citizens; these rates were not significantly different. Although some Turkish studies in the literature support these findings [11, 17], the available scientific evidence shows that being a refugee constitutes a disadvantage for neonatal weight $[8,9,15,18]$. The Republic of Turkey provides free health services to Syrian refugees and makes it easier for them to reach health resources. Easier
Table 2 Maternal and neonatal outcomes of Syrian and Turkish women with high-risk pregnancies

\begin{tabular}{llll}
\hline Variables & Turkish Citizens & Syrian Refugees & p value \\
\hline $\begin{array}{l}\text { Pregnancy result } \\
\text { Live birth }\end{array}$ & $221(94.8 \%)$ & $64(92.8 \%)$ & \\
Stillbirth & $3(1.3 \%)$ & $1(1.4 \%)$ & $0.616 \dagger$ \\
Miscarriage & $9(3.9 \%)$ & $4(5.8 \%)$ & \\
Mode of delivery* & & & $<0.001 \ddagger$ \\
Vaginal delivery & $92(41.1 \%)$ & $50(76.9 \%)$ & $0.891 \ddagger$ \\
C/S delivery & $132(58.9 \%)$ & $15(23.1 \%)$ & $0.086 \S$ \\
Gestational week $* *$ & & $6(9.4 \%)$ & \\
$<37$ weeks (Preterm birth) & $22(10.0 \%)$ & $58(90.6 \%)$ & $2980.2 \pm 395.0$ \\
$\geq 37$ weeks (Term birth) & $199(90.0 \%)$ & & \\
Birth weight** $(\mathrm{g})($ mean \pm std) & $3097.5 \pm 501.3$ & $2(3.1 \%)$ & $62(96.9 \%)$ \\
Low birth weight $* *$ & $17(7.7 \%)$ & & \\
$<2500 \mathrm{~g}$ & $204(92.3 \%)$ & & \\
$\geq 2500 \mathrm{~g}$ & & & \\
\hline
\end{tabular}

$C / S$ cesarean section, $g$ grams, mean \pm std mean \pm standard deviation

${ }^{\dagger}$ Fisher's exact test

${ }^{\ddagger}$ Chi-square test

${ }^{\S}$ Independent samples t test was applied

* Only for live births and stillbirths

** Only for live births 

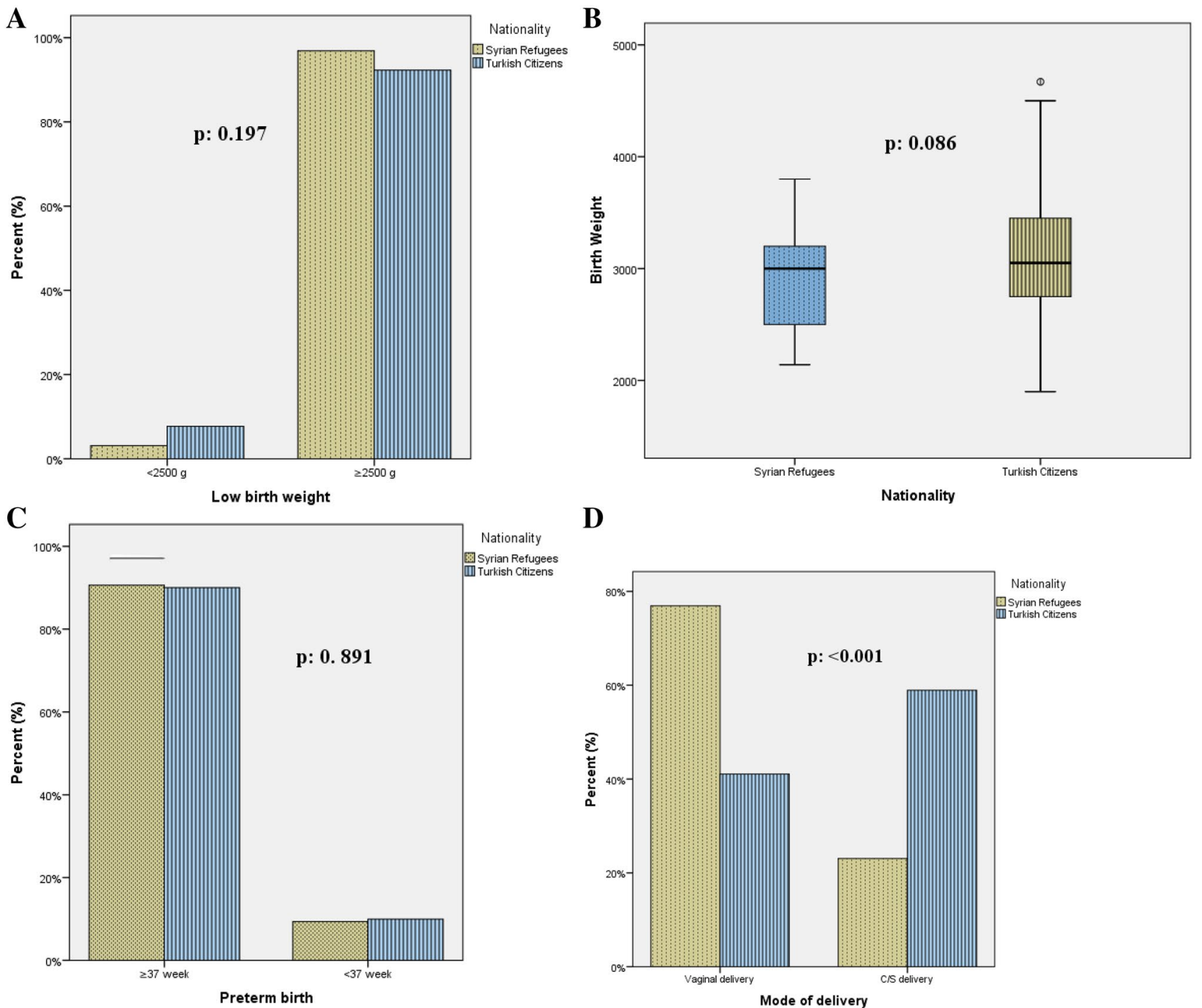

D

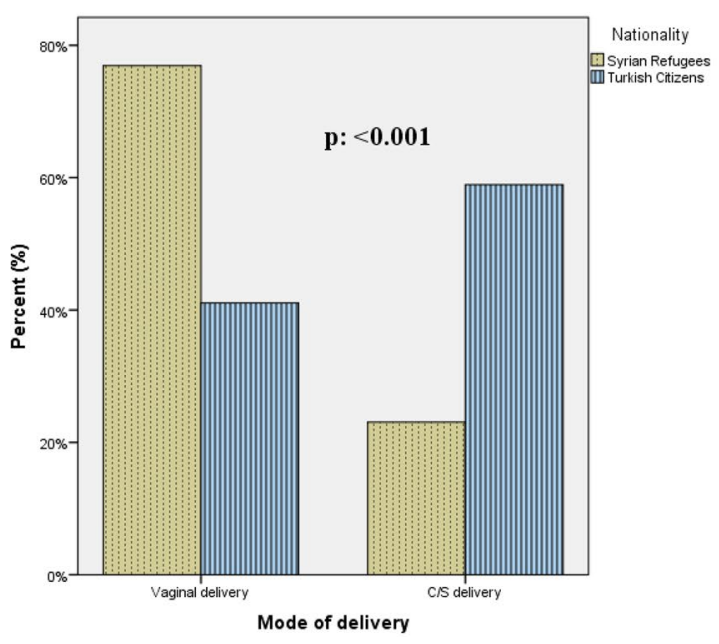

Fig. 2 A Low birth weight; B Birth weight; C Preterm birth; D Mode of delivery according to nationality

access to health services for refugees may minimize negative pregnancy outcomes. Additionally, Syrian refugees can adapt to Turkish society due to lengthened periods of staying in Turkey because they have highly positive perceptions, access to public services such as health care and education and present cultural similarities such as cultural values, language, religious and traditional beliefs [19].

Tappis et al. reported that the first antenatal care was provided during the 3rd and 4th months to Syrian refugees in Jordan and Lebanon, and the most important cause for not receiving antenatal care reported was the high expense [20]. Ozel et al. reported that only $23 \%$ pregnant Syrian refugees received antenatal care in 2015 in Ankara, Turkey [9]. Antenatal care with a gynecologist was reported in more than $90 \%$ of the Turkish citizens and Syrian refugees in this study. The median pregnancy week at the gynecologist visit was 8 weeks for Syrian refugees, which was significantly higher than that for Turkish citizens (6 weeks). Although the first antenatal care week is significantly higher for Syrian refugees than for Turkish citizens, 8 weeks for the first antenatal care week can be evaluated as appropriate. The WHO recommends eight antenatal care sessions for pregnant women, first during the first 12 weeks of pregnancy and then at 20, 26, 30, 34, 36, 38 and 40 weeks [4]. According to the "Prenatal Care Management Guideline" published by the Turkish Ministry of Health, a minimum of four follow-ups, first during the first 14 weeks of pregnancy, should be performed in pregnancies [5]. Early antenatal care visits are paramount for ensuring optimal health outcomes for women and children by providing effective evaluation, screening and treatment facilities (screening for genetic and congenital disorders, provision of folic acid and iron supplementation, evaluating 
Table 3 Results of logistic and linear regression analysis with unadjusted and propensity score-adjusted live births, preterm births, and birth weights among Syrian and Turkish women with high-risk pregnancies (ref: Turkish Citizens)

\begin{tabular}{|c|c|c|c|c|c|c|}
\hline \multirow[t]{2}{*}{ Output* } & \multicolumn{3}{|l|}{ Unadjusted } & \multicolumn{3}{|c|}{ Adjusted with propensity score } \\
\hline & $\operatorname{Exp}(B)$ & $(95 \% \mathrm{CI})$ & $\mathrm{p}$ value & $\operatorname{Exp}(B)$ & $(95 \% \mathrm{CI})$ & $\mathrm{p}$ value \\
\hline \multicolumn{7}{|c|}{ Model 1: Live birth } \\
\hline Syrian refugees & 0.695 & $0.236 / 2.046$ & 0.509 & 0.480 & $0.135 / 1.699$ & 0.255 \\
\hline \multicolumn{7}{|c|}{ Model 2: Preterm birth } \\
\hline Syrian refugees & 0.936 & $0.362 / 2.417$ & 0.891 & 1.108 & $0.320 / 3.833$ & 0.871 \\
\hline \multicolumn{7}{|c|}{ Model 3: Low birth weight $(<2500 \mathrm{~g})$} \\
\hline \multirow[t]{2}{*}{ Syrian refugees } & 0.387 & $0.087 / 1.722$ & 0.213 & 0.185 & $0.004 / 8.18$ & 0.383 \\
\hline & Coefficient (B) & $(95 \% \mathrm{CI})$ & $\mathrm{p}$ value & Coefficient (B) & $(95 \% \mathrm{CI})$ & $\mathrm{p}$ value \\
\hline
\end{tabular}

Model 4: Birth weight

Syrian refugees

$-117.3$

$-251.3 / 16.7$

0.086

$-124.5$

$-280.2 / 31.1$

0.116

Linear regression analysis was applied in model 4 and a logistic regression analysis was applied in models 1, 2, and 3. Dependent Variables Live birth, preterm birth, low birth weight, birth weight; Independent variables Nationality, propensity score: age, parity, abortion, pregnancy spacing shorter than 2 years, previous $\mathrm{C} / \mathrm{S}$, concurrent chronic disease, and gestational week at first antenatal gynecologist appointment

$C I$ confidence interval, $g$ grams

sexually transmitted infections and non-communicable diseases) [21].

In this study, the preterm birth history rate was $15 \%$ in Turkish citizens and $7.3 \%$ in Syrian refugees. In a study conducted on Syrian refugees in Turkey between 2013 and 2014, a preterm birth rate of $26 \%$ was reported [22]; this rate was reported to be lower in further studies but was higher in Syrian refugees than in Turkish citizens [9, 15, 23]. The preterm birth rates were not significantly different between Turkish citizens and Syrian refugees, with rates of $10.0 \%$ for Turkish citizens and 9.4\% for Syrian refugees. Preterm birth was also not different according to the adjusted propensity score between Turkish citizens and Syrian refugees. In many studies, the preterm rate is higher in Syrian refugees, which is attributed to insufficient antenatal care, education level, malnutrition, etc. $[9,15]$. Celik et al. reported that the preterm rate was not different between Turkish and Syrian refugees. [24]. Similar to birth weight, these results can be attributed to the fact that the refugees can receive adequate and free health services and because of their integration into the health and social structure.

The previous C/S rate was $40.1 \%$ in Turkish citizens and $21.7 \%$ in Syrian refugees based on this study. A high previous $\mathrm{C} / \mathrm{S}$ rate in Turkish citizens may be the cause of the high $\mathrm{C} / \mathrm{S}$ rate for these pregnancies. The $\mathrm{C} / \mathrm{S}$ rates were higher in Turkish citizens (58.9\%) than in Syrian refugees (23.1\%). This finding may be related to age, concurrent chronic diseases and globally increasing $\mathrm{C} / \mathrm{S}$ rates; a $\mathrm{C} / \mathrm{S}$ prevalence of $53.1 \%$ was reported for Turkey, making it one of the highest $\mathrm{C} / \mathrm{S}$ prevalence countries in the world $[25,26]$. High $\mathrm{C} / \mathrm{S}$ rates are reported in Turkey not only for health reasons but also due to income and social situations, network support, education and literacy, employment and working conditions, physical environment, lifestyle, behavior, gender and cultural influences [26].

Previous studies showed that pregnant Syrian refugees were younger than pregnant Turkish citizens. Similarly, the mean age was lower for pregnant Syrian refugees (28.1 \pm 6.4$)$ than for pregnant Turkish citizens $(31.4 \pm 6.9)$ in this study. Additionally, this study found a lower first pregnancy age and higher parity in Syrian refugees. The escape from war may have caused Syrian refugee families to prefer their daughters to marry at an early age as a way to protect them. This is how the increase in adolescent pregnancies during war times was interpreted in other studies [23].

While $52.7 \%$ of the Turkish citizens had pregnancy spacings shorter than two years, the rate was $69.4 \%$ in Syrian refugees. In a study conducted on Syrian refugees in Jordan, pregnancy spacing shorter than 2 years was reported in more than half of the refugees [27]. The pregnancy spacing is decreased by later marriage age, lower rate of contraception use, lower breastfeeding duration for the previous child, lower education level of the husband, the boy child preference of the mother, the presence of abortion or stillbirth in the preceding pregnancies, lower income sufficiency, and lower maternal awareness of optimum pregnancy spacing [28].

A meta-analysis study reported an unintended pregnancy prevalence of approximately $44 \%$ worldwide and $65 \%$ in developing countries [29]. Unintended pregnancies generally have negative outcomes for both mothers and infants [30]. The planned and intended pregnancy rate was $66.5 \%$ in Turkish citizens and $85.5 \%$ in the Syrian refugees in this study. A total of $52.2 \%$ of Syrian refugees planned to become pregnant again, while $22.7 \%$ of Turkish citizens did. Young age may be the cause of the high rates of intended 
pregnancy and for planning repeat pregnancy in Syrian refugees. The low rate of intended pregnancy in Turkish citizens may be due to cultural factors. The prevalence was reported to be $26 \%$ in Iran, which has a similar socioeconomic and religious structure [31].

This study had some limitations. First, our study data were compulsorily acquired from the patients through follow-ups on the phone due to the COVID-19 pandemic. Additionally, some of the patients kept more detailed data (hospital admission records, patient records, laboratory parameters, etc.) closed to online health systems access, and therefore, there was a large amount of missing data. Thus, the study could not include more detailed information on laboratory parameters or face to face evaluation and other serious maternal and neonatal outcomes, such as neonatal intensive care hospitalization, maternal bleeding, maternal hospitalization, etc.

As a second limitation, the participants were selected from among those who applied to any health center and were evaluated and followed up as women with high-risk pregnancies. If a pregnant Turkish or Syrian woman did not apply to a health center or did not report her pregnancy, she could not be included in the study, and information about these people could not be collected. The study was conducted in Sanliurfa, which has a lower socioeconomic status than that of the rest of Turkey. Therefore, the Turkish citizen population of the study may not reflect the entire Turkish community. At the end of the study, a power analysis was performed on birth weights. In this study, the difference in birth weights of Turkish and Syrian women with high-risk pregnancies was found to be narrower than the parameters used in the sample analysis. The power analysis was performed with birth weights at the end of the study. The power of the study was found to be $52 \%$. Although there was no difference in birth weights between Turkish citizens and Syrian refugees in this study, our results must be confirmed in larger study groups.

Despite these limitations, this study is the first cohort study on Turkish citizens and Syrian refugees with high-risk pregnancies. This study is unique in that it evaluates the clinical characteristics and pregnancy and neonatal data from refugees coming from Syria, where an active war continues.

In conclusion, pregnancy and neonatal outcomes, such as birth weight, preterm birth and live birth, were not significantly different between Turkish citizens and Syrian refugees with high-risk pregnancies in this study. A high $\mathrm{C} / \mathrm{S}$ rate was found among Turkish citizens. The Syrian refugees were younger and had higher parities. Action should be taken to remove barriers to accessing reproductive health and maternity services. Additionally, to overcome some social barriers, Syrian refugee women should be equipped with knowledge, skills and approaches at the individual level. Pregnant women with risk factors should be closely monitored, in both the local population and refugee communities. Many studies have shown barriers in access to health services for refugees from different countries, with an inaccessibility of health services due to their costs, but this was not observed in Turkey since the country provides health services to refugees without any limitations or charge.

Funding No funding was received for conducting this study. The study data were obtained from the project "Diagnosis and Follow-up of Risk/ High Risk Pregnancies of Women in Syrian and Host Communities" conducted in cooperation with the WHO Country Office (Turkey) (WHO Reference:2020/990728-0; Purchase Order:202498071). The WHO Country Office (Turkey) had no role in this study design, the results or the interpretations.

\section{Declarations}

Conflict of interest The authors declare that they have no conflicts of interest.

Ethical Approval This study was approved by the Clinical Research Ethics Committee of Harran University, School of Medicine (13.07.2020- HRU/20.13.13).

Informed Consent Informed consent (in Arabic or Turkish) was obtained from all individual participants included in the project. A second informed consent form was obtained from all participants for using data collected for the study.

\section{References}

1. The UN Refugee Agency. Syria Emergency. https://www.unhcr. org/syria-emergency.html. Accessed 18 Nov 2020.

2. Republic of Turkey, Ministry of Interior. Temporary protection. https://en.goc.gov.tr/temporary-protection27. Accessed 18 May 2021.

3. Mchenga M, Burger R, von Fintel D. Examining the impact of WHO's Focused Antenatal Care policy on early access, underutilisation and quality of antenatal care services in Malawi: a retrospective study. BMC Health Serv Res. 2019;19:295.

4. Nassar AH, Theron G, Wright A. FIGO statement: antenatal care and refugees. Int J Gynaecol Obstet. 2021;152(2):152-4.

5. Prenatal Care Management Guideline. Republic of Turkey, Ministry of Health, General Directorate of Public Health, 924, Ankara, 2014, https://sbu.saglik.gov.tr/Ekutuphane/kitaplar/dogumonuba kim.pdf. Accessed 18 Nov 2020.

6. Kiyak H, Gezer S, Ozdemir C, Gunkaya S, Karacan T, Gedikbasi A. Comparison of delivery characteristics and early obstetric outcomes between Turkish women and Syrian refugee pregnancies. Niger J Clin Pract. 2020;23(1):12-7.

7. Gissler M, Alexander S, MacFarlane A, et al. Stillbirths and infant deaths among migrants in industrialized countries. Acta Obstet Gynecol Scand. 2009;88(2):134-48.

8. Heslehurst N, Brown H, Pemu A, Coleman H, Rankin J. Perinatal health outcomes and care among asylum seekers and refugees: a systematic review of systematic reviews. BMC Med. 2018;16:89.

9. Ozel S, Yaman S, Kansu-Celik H, Hancerliogullari N, Balci N, Engin-Ustun Y. Obstetric outcomes among syrian refugees: a comparative study at a Tertiary Care Maternity Hospital in Turkey. Rev Bras Ginecol Obstet. 2018;40(11):673-9. 
10. Samari G. Syrian refugee women's health in Lebanon, Turkey, and Jordan and recommendations for improved practice. World Med Health Policy. 2017;9(2):255-74.

11. Erenel H, Mathyk BA, Sal V, Ayhan I, Karatas S, Bebek AK. Clinical characteristics and pregnancy outcomes of Syrian refugees: a case-control study in a tertiary care hospital in Istanbul, Turkey. Arch Gynecol Obstet. 2017;295(1):45-50.

12. Simsek Z, Yentur Doni N, Gul Hilali N, Yildirimkaya G. A community-based survey on Syrian refugee women's health and its predictors in Şanliurfa, Turkey. Women Health. 2018;58(6):617-31.

13. Liu C, Ahlberg M, Hjern A, Stephansson O. Perinatal health of refugee and asylum-seeking women in Sweden 2014-17: a register-based cohort study. Eur J Public Health. 2019;29(6):1048-55.

14. Fırtına Tuncer S, Timur B, Yalvaç ES, Mollamahmutoğlu L. Predictors of adverse maternal and perinatal outcomes in a refugee population from an active conflict country, Syria. Turk J Obstet Gynecol. 2019;16(3):174-9.

15. Turkay Ü, Aydın Ü, Salıcı M, et al. Comparison of pregnant Turkish women and Syrian refugees: does living as a refugee have an unfavorable effect on pregnancy outcomes? Int J Gynaecol Obstet. 2020;149(2):160-5.

16. Turkish Statistical Institute. https://biruni.tuik.gov.tr/medas/?kn= $113 \&$ locale $=$ tr. Accessed 18 May 2021.

17. Güngör ES, Seval O, İlhan G, Verit FF. Do Syrian refugees have increased risk for worser pregnancy outcomes? Results of a tertiary center in İstanbul. Turk J Obstet Gynecol. 2018;15(1):23-7.

18. Demirci H, Yildirim Topak N, Ocakoglu G, Karakulak Gomleksiz M, Ustunyurt E, Ulku TA. Birth characteristics of Syrian refugees and Turkish citizens in Turkey in 2015. Int J Gynaecol Obstet. 2017;137(1):63-6.

19. Şafak-Ayvazoğlu A, Kunuroglu F, Yağmur K. Psychological and socio-cultural adaptation of Syrian refugees in Turkey. Int J Intercult Relat. 2021;80:99-111.

20. Tappis H, Lyles E, Burton A, Doocy S. Maternal health care utilization among Syrian refugees in Lebanon and Jordan. Matern Child Health J. 2017;21(9):1798-807.

21. Moller AB, Petzold M, Chou D, Say L. Early antenatal care visit: a systematic analysis of regional and global levels and trends of coverage from 1990 to 2013. Lancet Glob Health. 2017;5(10):e977-83.
22. Büyüktiryaki M, Canpolat FE, Dizdar EA, Okur N, Şimşek GK. Neonatal outcomes of Syrian refugees delivered in a tertiary hospital in Ankara, Turkey. Confl Health. 2015;9:38.

23. Turkay Ü, Aydın Ü, Çalışkan E, Salıcı M, Terzi H, Astepe B. Comparison of the pregnancy results between adolescent Syrian refugees and local adolescent Turkish citizens who gave birth in our clinic. J Matern Fetal Neonatal Med. 2020;33(8):1353-8.

24. Celik IH, Arslan Z, Ulubas-Isik D, et al. Neonatal outcomes in Syrian and other refugees treated in a tertiary hospital in Turkey. Turk J Med Sci. 2019;49(3):815-20.

25. Betrán AP, Ye J, Moller A-B, Zhang J, Gülmezoglu AM, Torloni MR. The increasing trend in caesarean section rates: global, regional and national estimates: 1990-2014. PLoS ONE. 2016;11(2):e0148343.

26. Santas G, Santas F. Trends of caesarean section rates in Turkey. J Obstet Gynaecol. 2018;38(5):658-62.

27. Price M, Safadi R, Clements D. Reproductive health experiences of Syrian refugees residing in Jordan. J Midwifery Reprod Health. 2020;8(4):2437-46.

28. Dehesh T, Salarpour E, Malekmohammadi N, Kermani SA. Associated factors of pregnancy spacing among women of reproductive age Group in South of Iran: cross-sectional study. BMC Pregnancy Childbirth. 2020;20:554.

29. Bearak J, Popinchalk A, Alkema L, Sedgh G. Global, regional, and subregional trends in unintended pregnancy and its outcomes from 1990 to 2014: estimates from a Bayesian hierarchical model. Lancet Glob Health. 2018;6(4):e380-9.

30. Mohamed EAEB, Hamed AF, Yousef FMA, Ahmed EA. Prevalence, determinants, and outcomes of unintended pregnancy in Sohag district, Egypt. J Egypt Public Health Assoc. 2019;94:14.

31. Sayehmiri K, Ebtekar F, Zarei M, Gheshlagh RG. Prevalence of unwanted pregnancy among Iranian women: an updated metaanalysis. BMC Pregnancy Childbirth. 2019;19(1):491.

Publisher's Note Springer Nature remains neutral with regard to jurisdictional claims in published maps and institutional affiliations. 